Please quote as: Kipp, P.; Wieck, E.; Bretschneider, U. \& Leimeister, J. M. (2013): 12 Years of GENEX Framework: What did Practice Learn from Science in Terms of Web-Based Ideation?. In: Wirtschaftsinformatik Konferenz (WI) 2013, Leipzig, Germany. 


\title{
12 Years of GENEX Framework: What did Practice Learn from Science in Terms of Web-Based Ideation?
}

\author{
Philipp Kipp ${ }^{1}$, Enrico Wieck ${ }^{1}$, Ulrich Bretschneider ${ }^{1}$, and Jan Marco Leimeister ${ }^{1}$ \\ ${ }^{1}$ Kassel University, Information Systems, Kassel, Germany \\ \{philipp.kipp, wieck, bretschneider, leimeister\}@uni-kassel.de
}

\begin{abstract}
In Open Innovation, companies open up their innovation activities to external stakeholders. Using web-based ideation platforms (WBIP), companies crowdsource ideas for innovations from their customers. Ideation can be considered as a create process. Therefore, in this research we analyze how current web-based ideation platforms run by firms support Shneiderman's GENEX framework that aims at supporting creativity in information systems. By doing so, we were able to identify the state-of-the-art in practice as well as further research areas. We analyzed 16 web-based ideation platforms in total. Results indicate that current WBIP use creativity tasks different intensive and that some GENEX tasks are already well implemented, while others require further research. Results are discussed and theoretical and practical contributions, limitations and identified research questions provided.
\end{abstract}

Keywords: IT-supported creative work, Open Innovation, web-based ideation platform, GENEX framework.

\section{Introduction}

After Henry Chesbrough coined the term "Open Innovation" in 2003, many companies and organizations started opening up their innovation activities to external stakeholders [1]. Especially the integration of customers, suppliers or the general public into the tasks of idea development and elaboration proved to be a powerful tool for increasing a company's innovativeness [2], [3]. These stakeholders of the company have specific insights into the products, services and processes of the company. Therefore, external stakeholders are capable of involving into ideation that leads to both radical and gradual innovation [3-5].

Using specific web-based platforms that enable collaborative ideation via the Internet, it has been possible to address large groups of customers at very low cost. Since the early 2000s, many companies run web-based ideation platforms (WBIP) in the guise of virtual idea communities or online idea competitions to integrate their customers into their ideation processes [6], [7]. WBIPs provide customers a tool to

$11^{\text {th }}$ International Conference on Wirtschaftsinformatik,

$27^{\text {th }}$ February $-01^{\text {st }}$ March 2013, Leipzig, Germany 
share their ideas and to elaborate these ideas collaboratively regarding the company's products and services adopting the principle of crowdsourcing [8], [9].

Ideation in virtual ideas communities and online idea competitions can be characterized as a creative task. In order for the platform's participants to perform well in these creative tasks, it is necessary to support creativity by suitable features on the platform. The GENEX framework published by Ben Shneiderman in 2002 revealed important requirements in terms of supporting ideation via the Internet [10], [11]. The Shneiderman article describes how creativity in information systems can be seen as a collection of different tasks and actions, which can individually be supported by features and the overall design of an information system [10]. This article drew some attention when it was first published [7], [12]. As WBIT can be considered as an information system, we find the GENEX framework suitable and established for evaluation of the creativity support especially for ideation via WBIT applied for above mentioned idea communities or idea competitions.

Against this backdrop, this paper analyzes existing WBIP. This analysis concentrates on the identification of features and design artifacts on the platforms, which support the individual tasks and activities described in the GENEX framework. A first collection of possible features has already been done by Huber et al. [13]. But the features found in the paper by Huber et al. have not yet been mapped to existing WBIP, thus missing an evaluation of the Shneiderman framework's impact on the design of such platforms.

This leads to the following research questions:

RQ1: Which parts of Shneiderman's framework, which can be considered as requirement in terms of creativity via the Internet, are already realized in current WBIPs in practice?

RQ 2: Which parts are missing and therefore represent starting points for future research regarding the creativity support on those platforms?

\section{Theoretical Background: Shneiderman's GENEX framework}

A challenge for human-computer interaction researchers and user interface designers is to construct information technologies that support creativity. This was the starting point for Shneiderman to develop a framework for creativity that might assist IS designers in providing effective tools for users [11]. Shneiderman developed a theoretical framework by building on an adequate understanding of creative processes. Therefore, his so-called GENEX framework proposes four basic activities representing the process of creative work [10], [11]. These four activities, namely collect, relate, create and donate, are defined by eight smaller tasks. Fig. 1 displays the four activities as well as the according tasks.

The purpose of the "collect" activity is to support people in learning from previous work on the field of the task they are supposed to perform. Therefore, the "collect" activity represents the tasks "Searching and browsing digital libraries" and "Visualizing data and processes" for making such work accessible and comprehensi- 
ble. Thereby, information can be represented by various types of media such as photos, movies, sound files or plain text. IT that supports the "collect" activities should enable interpretation, representation and ascertainability of these heterogeneous information and also their interrelations in an effective and efficient way.

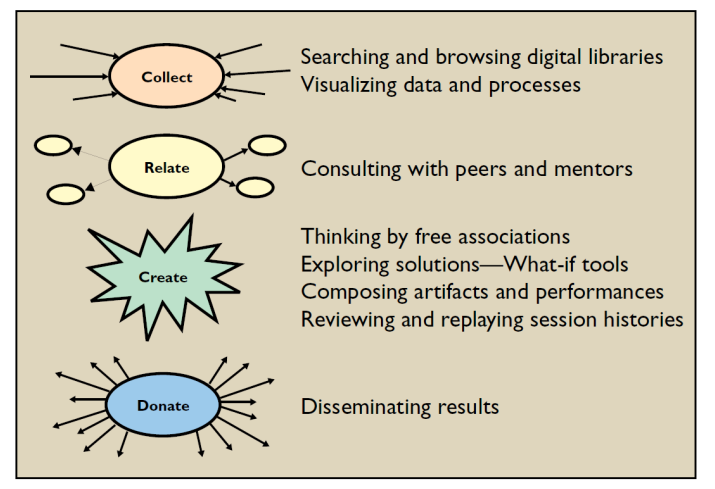

Fig. 1. Creativity activities and tasks [10]

The "relate" activity describes the task of consulting with peers and mentors when being creative. Communication and knowledge exchange with both experts and peers facing similar or same tasks is critical for the success of creative work. Therefore, IT support should offer functionalities that enables creative workers and mentors to communicate with each other.

The "create" activity concludes all tasks that directly support the creation of creative work. IT support for the "create" activities should allow the users enough freedom to create and represent their creative products in the way they deem appropriate, but at the same time give enough structure to guide the user towards feasible and useful contributions.

The "donate" activity concludes IT support that allows the dissemination of creative products, namely the work results. IT support should allow users to present their work results and allow for a good overview over the submitted contributions. Also, such support should allow users in communicating their work to others.

\section{Mapping the GENEX Framework to Web-based Ideation Platforms: A framework for our research}

As mentioned, WBIP aims at enabling a collective ideation among customers of firms, which run such WBIP for integrating their customers into the early stages of their innovation processes, namely the ideation phase, according to the Open Innovation principle. More generally speaking, WBIP supports the development and collaborative elaboration of ideas among a relatively high amount of users via the Internet. 
Typically, customers submit ideas and/or connect with other idea contributors to collaboratively elaborate submitted ideas.

The activities of customers involved in such innovation value creating are highly creative and activate an individual's creative process [14]. Because of this it is possible to apply the GENEX framework to WBIP. Applying the GENEX framework to the field of WBIP provides us with a framework for our analysis. In the following we systematically map this specific case of ideation, respectively creative work to the eight tasks out of Shneiderman's GENEX framework.

Applying the "collect" activity to the domain of ideation covers learning from ideas that have been previously submitted by other customers. Therefore, applying the "searching and browsing" task to our context means that WBIP should provide digital libraries where privous ideas are collected. Furthermore, customers should be provided with functionalitiy that allows to search for an idea, for example by using a search engine with a search string or using a tag cloud. Furthermore, search tasks can be supported by filtered views of data for example using table filters. As it concerns "visualizing" this task overlaps with the "searching and browsing" tasks in our context as "visualizing" tasks is described by Shneiderman as ,drawing mental or concept maps of current knowledge helps users organize their knowledge, see relationships, and possibly spot what is missing" [10]. In the domain of ideation via WBIP these tasks can also be supported by functionalities such as tag clouds or search engines mentioned above. Because of this, for our framework we merged both tasks into a single category, which we call "searching and visualizing" task.

Applying the "relate" activity, respectively its "consulting" task to our context means communicating and interacting with peers when collaboratively developing ideas or communicating with mentors supporting customers when developing ideas. This has been implemented on WBIP using functionalities like chats, message boards or messaging systems. Additionally some WBIP offered assistance in ideation by giving the opportunity to communicate with company employees involved with innovation.

Applying the "create" activity to the domain of ideation covers tasks that directly support the developing ideas. In terms of the "thinking" task Shneiderman demanded "tools that support their free association that helps to break free from their current mind set" [10]. In our context this can be realized by offering inspiration to the users such as displaying background information, examples, articles, pictures, videos and user stories etc. The "exploring" task covers conduction of "thought experiments about the implications of decisions" and simulations [10]. Since ideas can be very abstract and high level without much detail this is hardly adaptable to our context and we did not include this task into our framework. In terms of the "composing" task in our context an idea on a WBIP can be composed by different means, for example using a title, text, categorization, pictures, videos, tags, files and/or other means. According to the GENEX framework, the "reviewing" task spans ,the capacity to record activities, review them, and save them for future use. This list lets users return to previous steps and so supports the creativity process" [10]. In our context this could be applied to the collaborative development process of ideas so that different stages of 
the idea development should be recorded, reviewed, and saved for future idea development.

Applying the "donate" activity, respectively the "disseminating" task to the domain of ideation covers spreading ideas to others, e.g., peers and mentors. Thus, ideas can serve as artifact for other customers as basis for their creative work. WBIPs in practice often implemented this by offering means to share ideas not only among the WBIP users but also other (social) networks like Facebook, Google+ etc.

\section{$4 \quad$ Identifying WBIP in the Internet}

\subsection{Method}

In order to be included into this study, the following requirements needed to be fulfilled:

- The WBIP aims at the outside-in process of the early phase of the innovation funnel, i.e. to gather innovative ideas from customers or other stakeholders outside the organization.

- The WBIP is run by the organization that wants to gather the ideas. Thus, intermediaries and others are excluded where customers can propose solutions for concrete problems defined in advance by the organization.

- For WBIP it is necessary for them to still be running and accepting ideas to be included in the study. Otherwise it would not be possible to understand the all platform features.

At first, a Google search with the strings "idea community" as well as the German equivalent "Ideen community" was conducted to reveal current communities in practice. Further communities were added as they were not found through the Google search but known by us. In order to increase the diversity of WBIP, we also searched for WBIP tool providers, i.e. companies that produce and offer WBIP tools to others. We then considered one WBIP in practice for each WBIP provider included into this study. Including multiple WBIP for each provider would not further broaden the WBIP as they are build on the same technological base and thus provide the same features.

Using this dual approach for WBIP selection, a wide range and thus the most common current WBIP technologies are considered within this study. We conducted the WBIP search in June 2012.

\subsection{Results}

Eleven WBIP were found through the Google search and by adding communities that are known to us. They are listed in Table 1. 
Table 1. Identified WBIP after first iteration

\begin{tabular}{l|l} 
Associated Organization & WBIP \\
\hline Starbucks & http://mystarbucksidea.force.com \\
\hline Dell & http://www.ideastorm.com \\
\hline GFI & http://ideas.gfi.com \\
\hline Tchibo & https://www.tchibo-ideas.de \\
\hline SAP & http://www.sapiens.info \\
\hline TechSmith & https://ideenlabor.o2online.de \\
\hline Avid & http://camtasia.ideascale.com \\
\hline Nagios & http://protools.ideascale.com \\
\hline Swisscom & http://ideas.nagios.org \\
\hline Ford & http://labs.swisscom.ch \\
\hline
\end{tabular}

The search results for WBIP providers are shown in table 2 with each one WBIP in practice that is available to the public via Internet.

Table 2. WBIP providers and corresponding example WBIP

\begin{tabular}{l|l|l|l}
$\begin{array}{l}\text { WBIP } \\
\text { provider }\end{array}$ & WBIP Homepage & Organization & WBIP example \\
\hline $\begin{array}{l}\text { Salesforce.c } \\
\text { om }\end{array}$ & $\begin{array}{l}\text { http://www.salesforce.com/ } \\
\text { crm/customer-service- } \\
\text { support/ideation/ }\end{array}$ & Starbucks & $\begin{array}{l}\text { http://mystarbucksidea.force.co } \\
\mathrm{m} /\end{array}$ \\
\hline $\begin{array}{l}\text { IdeaScale } \\
\text { Hyve Idea- } \\
\text { Net }\end{array}$ & www.hyve.de/ideanet.php & Gemeinsam Selten & http://www.gemeinsamselten.de \\
\hline $\begin{array}{l}\text { Innovation- } \\
\text { Factory }\end{array}$ & $\begin{array}{l}\text { http://www.innovationfactory } \\
\text { eu/ }\end{array}$ & Heineken & http://ideasbrewery.com/ \\
\hline $\begin{array}{l}\text { IdeaJam } \\
\text { http://ideajam.net }\end{array}$ & OpenNTF & $\begin{array}{l}\text { http://openntf.org/ideajam/ideaja } \\
\text { m.nsf }\end{array}$ \\
\hline $\begin{array}{l}\text { BrightIdea } \\
\text { http://www.brightidea.com }\end{array}$ & Adobe & $\begin{array}{l}\text { http://na5.brightidea.com/ct/s.bi } \\
\text { x?c=8FBBEA8F-D8E6-4E34- } \\
\text { A7C1-7C74FB3B4EFA }\end{array}$ \\
\hline $\begin{array}{l}\text { Google } \\
\text { Moderator }\end{array}$ & www.google.com/moderator & Minecraft & $\begin{array}{l}\text { http://www.google.com/moderat } \\
\text { or/\#16/e=1c111 }\end{array}$ \\
\hline $\begin{array}{l}\text { Atizo } \\
\text { https://ideenlabor.o2online.de/ }\end{array}$
\end{tabular}




\section{WBIP Analysis}

The WBIP were each independently analyzed and evaluated by two researchers regarding their support of the activities and tasks described in the GENEX framework. At the end, each researcher assigned either an empty, half-full or full point indicating how the WBIP supports each task within the GENEX framework. This evaluation was based on the features and descriptions in section 3. If an effort to support the respective task was obvious from the design of the WBIP a full point was given. Offering only some features supporting a task without a recognizable focus on promoting the functionality a half-point was assigned to the WBIP regarding the task. If the task was not supported at all, we assigned an empty point. Results of both researchers' analysis were consolidated afterwards by making up the mean of both researchers' results.

Table 3. Results of platform analysis

\begin{tabular}{|c|c|c|c|c|c|c|c|}
\hline & 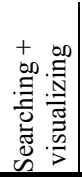 & 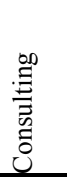 & : & $\begin{array}{l}\infty \\
: \equiv \\
0 \\
0 \\
0 \\
0 \\
0 \\
0\end{array}$ & 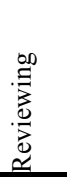 & 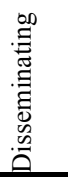 & $\stackrel{\text { ฮี }}{\Sigma}$ \\
\hline camtasia.ideascale.com & $\bullet$ & - & 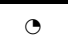 & - & - & $\bullet$ & 2,33 \\
\hline ideas.gfi.com & - & - & 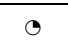 & - & - & - & 2,33 \\
\hline ideas.nagios.org & - & - & 0 & - & - & $\bullet$ & 2,33 \\
\hline ideasbrewery.com & $\bullet$ & - & - & • & - & ๑ & 3 \\
\hline labs.swisscom.ch & - & $\bullet$ & $\bullet$ & 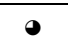 & - & $\bullet$ & 3 \\
\hline mystarbucksidea.force.com & $\bullet$ & - & $\odot$ & - & $\bullet$ & $\bullet$ & 2,83 \\
\hline $\begin{array}{l}\text { na5.brightidea.com/ct/s.bix?c=8F } \\
\text { BBEA8F-D8E6-4E34-A7C1- } \\
\text { 7C74FB3B4EFA }\end{array}$ & - & - & $\odot$ & - & - & $\bullet$ & 2,5 \\
\hline openntf.org/ideajam/ideajam.nsf & - & - & 0 & - & - & 9 & 1,67 \\
\hline protools.ideascale.com/ & $\bullet$ & - & ○ & - & $\bullet$ & $\bullet$ & 2,5 \\
\hline social.ford.com/your-ideas & $\bullet$ & - & - & - & O & $\bullet$ & 2,5 \\
\hline $\begin{array}{l}\text { www.google.com/moderator/\#16/e } \\
=1 \mathrm{c} 111\end{array}$ & $\bullet$ & - & ○ & - & O & $\odot$ & 1,33 \\
\hline www.ideastorm.com & $\bullet$ & $\bullet$ & - & - & - & $\bullet$ & 3 \\
\hline www.sapiens.info & - & - & O & - & - & - & 1,67 \\
\hline $\begin{array}{l}\text { forum.o2online.de/t5/Ideen- } \\
\text { f\%C3\%BCr-o2/idb- } \\
\text { p/IdeaExchange }\end{array}$ & • & - & o & - & - & - & 2 \\
\hline gemeinsamselten.de & $\bullet$ & $\bullet$ & - & - & O & $\odot$ & 2,33 \\
\hline www.tchibo-ideas.de & $\bullet$ & $\bullet$ & $\bullet$ & - & - & - & 3,17 \\
\hline Mean & 3,31 & 2,63 & 1,38 & 2,25 & 1,94 & 2,94 & \\
\hline
\end{tabular}


The degree of support of Shneiderman's tasks was analyzed for the final list of relevant platforms as identified in the previous sections. Table 3 displays the combined results of the analysis and is the basis for the further elaboration and discussion of the study results. The mean values displayed in the table are the mean values for the corresponding row or column. The following values have been assigned to the different circles: $\circ=0, \bullet=1, \bullet=2, \bullet=3, \bullet=4$.

\section{$5.1 \quad$ Results}

The mean values of Table 3 show, that the degrees of support for the different tasks defined by Shneiderman differ a lot (variance between means $=0,49$ ), while the evaluations of the different platforms are more homogeneous (variance between means $=$ $0,285)$. This can be seen as an indicator, that most of the platforms have a very similar degree of support for Shneiderman's creativity tasks, while the overall support for the tasks differs on all platforms. Since the purpose of the platforms is very similar, this is not a very surprising result, but it shows that the platforms seem to learn from each other and adopt successful features from other platforms to evolve.

When comparing the mean values for the task support it is obvious, that the searching task is very well supported by most platforms. The reason for this is that a lack of working search functionality makes it virtually impossible to use the site at all. Therefore this feature is basically mandatory for any website offering a collection of information. Additionally it is worth mentioning that there already is a lot of know-how regarding information management and search algorithms from almost every other kind of web-based platforms like search engines, wikis or discussion boards.

The consulting task is mainly covered by communication features on the technology side. It can be supported by any means of communication among participants and between participants and organization representatives. Most platforms in this study implemented message systems for the users to communicate with each other and feedback mechanisms like a promote/demote or simple rating system although current research gives reason to doubt the effectiveness of those measures to identify quality ideas [15]. The highly ranked platforms for this task offered support for the idea generation process by employees available for public or private discussion. This can for example be found on the DELL Ideastorm platform (ideastorm.com). Some other platforms augmented their online idea generation with offline events and workshops to improve and guide the idea generation performed by the participants.

We also found the thinking task not to be very well supported on many platforms, although several platforms showed that a good support for this task can be achieved by providing good examples, problems and inspiration for the participants. We assume that this is not provided by all platforms to the high effort for creation and maintenance of the necessary content. There do not seem to be any technical issues in the implementation of features supporting the thinking task of the GENEX framework. 
The task of composing is critical on ideas communities. The central purpose of the platforms is supporting the user in composing and submitting their ideas in a way that helps the organization to understand and implement the idea. Therefore the task was supported by every platform within the scope of this study. Although every platform offered features for entering an idea to their users, the possibilities for the individual representation were very different. Some platforms like camtasia.ideascale.com only offered a single text box for the idea, while other platforms like www.tchibo-ideas.de offered a rich input form that distinguishes between ideas for demand information (Problems) and solution information (Solutions) and give the participants the chance of uploading images or additional files to show display and present their ideas. The composing task offers some possibly very interesting research questions regarding the influence of rich idea generations forms on the quality of ideas generated on the platform.

The reviewing task comprises of features for bookmarking and saving content on the platforms (i.e. ideas) as well as elaboration features like wikis or comments and feedback functionality from the organization running the platform. Most platforms supported reviewing features of some sort. But it is apparent that comments and wikilike elaboration features are not very much used by the users on most WBIPs. The other feedback direction - the company giving feedback on the idea implementation status is also very well supported by the platforms in the study. Although the feature is available on 13 of the 16 platforms in the study, there are 4 platforms that do not seem to use the feature, which leads to empty categories for reviewed or implemented ideas. This is, besides the thinking task, one example of support for creativity tasks some platforms do not support likely for reasons of community management effort.

The purpose of the disseminating task is to spread ones ideas and share them not only with the company running the platform, but also with other members of the communities and people outside of the WBIP. This task is supported by every platform in this study, because every platform gives at least the option to see the ideas of other participants. Due to the widespread use of social networks, most of the platforms also offer to share ones ideas on social networking or microblogging sites like Facebook and Twitter. This not only motivates participants to generate new ideas. It also serves as a multiplicator to make the platforms widely known within the social networks of their participants, thus reaching more possible contributors of good ideas.

The analysis shows that the degree of support differs between the GENEX tasks. Especially the tasks searching and thinking stand out. While the searching task is very well supported by most platforms, the thinking task is only supported by few WBIPs. The reasons for these differences are very different, though. Searching algorithms and organizations of categorization are very common on almost any type of current online platforms and can be included using standard code without much effort. Support of the thinking task however requires a lot of effort on the side of the company. In order to support this task ideally we suggest a constant stream of content in order to stimulate the creativity of the participants. This can be done in form of texts, images, videos or audio streams, which all take a lot of resources to produce. 
Another task that promised very interesting results was the composing task. While a very rich support of this task by providing image and video upload along with tagging and a categorization and a topic specific text input form would technically be feasible for every platform, many decided only to offer short text passages. This decision can have multiple reasons: Text can be collected and transferred to other internal software systems more easily. The barrier for possible participants is lower when the input form is shorter. Keeping in mind, that some of the platform decided to have a very simple idea input form, while others offer a lot of multimedia support it might be an interesting research opportunity to research the influence of richer idea input forms on participation, motivation and idea quality.

\section{Future Research in the Field of WBIP}

This study indicates that the support of the different tasks and actions of the GENEX framework in the field of WBIP differs significantly between tasks. The tasks searching, consulting and disseminating are in many cases well implemented. On the one hand this is because the necessary technology for the support of this task can be seen as a commodity. Search algorithms for example are very well researched and are implemented throughout any kind of web based platform. From the perspective of this study there are no important open research questions regarding the implementation of these tasks of the GENEX framework in WBIPs.

The other tasks, namely thinking, composing and reviewing offer some interesting opportunities for future research. All of these tasks have in common that their implementations on the WBIPs included in this study were very inhomogeneous. While some platforms obviously spend a lot of effort implementing some or all of these tasks, other platforms did not. This is even true for the composing task, which is the key task in supporting the user to participate on a WBIP by composing their ideas.

In order to find interesting research questions regarding the implementation of these tasks we looked at our results from three different perspectives:

1. What are the reasons for implementing or not implementing the tasks as suggested by Shneiderman? [10]

2. Does the implementation of features according to the GENEX framework improve creativity among WBIP participants?

3. Does the implementation of the GENEX tasks lead to better ideas in WBIPs? The reasons for the support or lack thereof have to be analyzed for every task individually. The implementations of the thinking task in the analyzed platforms are mostly based on providing example ideas, best practices or inspiring videos. All of this is content, which takes a lot of resources for creation. An approach for future research at this point could be a qualitative study among companies running WBIP to further quantify the cost to provide the material and the expected gain the companies hope to achieve.

As mentioned before, the creative task of composing content (i.e. ideas) is central for the functionality of WBIP. The platforms support this task by providing input 
forms or other kinds of editors to their participants. Our study showed that the degree of freedom and detail these forms offer to the user differs a lot between platforms. Reasons for this can be manifold. One possible reason is that there are technical limitations coming from idea management software used to process and archive the user generated ideas. Another reason might be that the designers wanted to keep the platform as simple as possible and therefore accepted simpler idea representations without images, videos or structured text. Future research focusing on the composing task could concentrate on the question, if rich idea representations are generally the better choice for WBIPs and if not, what are the factors influencing the usefulness of rich input forms?

Another task that was implemented in very different ways by the platforms is the reviewing task. This task describes features that help users to reference, save or edit ideas generated by other users. Some platforms simply implemented bookmarking features allowing users to save ideas for later reference. Other platforms went further and implemented wiki-like features to edit ideas other users contributed. Additionally those platforms offered version histories and undo functionality for unwanted changes. This approach shows that there is room for collaboration among WBIP contributors. This gives interesting opportunities for future research regarding online collaboration. Future research could focus on how to motivate users to elaborate ideas of other users or on the development of tool supported processes aiming on the structured elaboration of ideas on WBIPs.

\section{Conclusion}

In the introduction we posed two research questions leading the course of this study. The first question aimed at the adoption of the GENEX framework in common WebBased Ideation Platforms. The study showed that some of the tasks are very well implemented throughout all the analyzed platforms, while other tasks are only implemented by fewer platforms or in very different ways on different platforms.

The second research question focused on the identification of future research opportunities in the field of creativity support on WBIPs. This question was answered by pointing out a series of interesting research questions regarding the reasons for different implementations, the effect of those implementations on idea quality and the support of user collaboration on WBIPs [16].

\subsection{Limitations}

Even though we tried to eliminate as much limitations as possible, we acknowledge that there are still limitations of our study.

First, due to the fast pace in IT it might be possible that there are WBIP that we did not include in our study. These might include functions supporting creativity that none of the communities we considered have. However, we are convinced that our 
results show a representative picture of the current state-of-the art due to our dual approach for WBIP selection.

Second, the idea communities were evaluated independently by two researchers only. Even though the results were somewhat different but without great discrepancies, it might increase result validity if more researchers would evaluate the communities.

Third, we analyzed the communities regarding their consideration of the GENEX framework only. This does not cover any qualitative research about the business concepts, the degree the WBIP fulfill their demand, if these communities can be considered successful or others research questions. 


\section{References}

1. Chesbrough, H.W.: The Era of Open Innovation. MIT Sloan Management Review 44, $34-$ $41(2003)$

2. von Hippel, E.: Democratizing Innovation. The MIT Press, Cambridge, MA (2005)

3. Reichwald, R., Piller, F.: Interaktive Wertschöpfung - Open Innovation, Individualisierung und neue Formen der Arbeitsteilung. Gabler, Wiesbaden (2009)

4. Gassmann, O., Enkel, E.: Open Innovation: Die Öffnung des Innovationsprozesses erhöht das Innovationspotenzial. Zeitschrift für Führung und Organisation 74, 132-138 (2006)

5. Soll, J.H.: Ideengenerierung mit Konsumenten im Internet. Deutscher Universitätsverlag, Wiesbaden (2006)

6. Bretschneider, U.: Die Ideen Community zur Integration von Kunden in die frühen Phasen des Innovationsprozesses: Empirische Analysen und Implikationen für Forschung und Praxis. Springer Gabler, Wiesbaden (2012)

7. Leimeister, J.M., Huber, M., Bretschneider, U., Krcmar, H.: Leveraging Crowdsourcing: Activation-Supporting Components for IT-Based Ideas Competition. Journal of Management Information Systems 26, 197-224 (2009)

8. Howe, J.: Crowdsourcing: How the power of the crowd is driving the future of business. Crown Business Publishing, New York (2008)

9. Surowiecki, J.: The Wisdom of Crowds: Why Many are Smarter Than the Few and How Collective Wisdom Shapes Business, Economie, Societies and Nations. Doubleday, New York (2004)

10. Shneiderman, B.: Creativity Support Tools. Communications of the ACM 45, 116 - 120 (2002)

11. Shneiderman, B.: Creating Creativity: User Interfaces for Supporting Innovation. ACM Transactions on Computer-Human Interaction 7, 114-138 (2000)

12. Tiwana, A., Mclean, E.R.: Expertise Integration and Creativity in Information Systems Development. Journal of Management Information Systems 22, 13-43 (2005)

13. Huber, M., Bretschneider, U., Leimeister, J.M., Krcmar, H.: Making Innovation happen: Tool-support for software related Communities for Innovations. International Reports on Socio-Informatics - Open Design Spaces Supporting User Innovation. International Workshop on Open Design Spaces (ODS), Bonn (2009)

14. Amabile, T.M., Conti, R., Coon, H., Lazenby, J., Herron, M.: Assessing the Work Environment for Creativity. Academy of Management Journal 39, 1154-1184 (1996)

15. Riedl, C., Blohm, I., Leimeister, J.M., Krcmar, H.: Rating scales for collective intelligence in innovation communities: Why quick and easy decision making does not get it right. ICIS 2010, (2010)

16. Dean, D.L., Hender, J.M., Rodgers, T.L., Santanen, E.L.: Identifying Quality, Novel, and Creative Ideas: Constructs and Scales for Idea Evaluation. Journal of the Association of Information Systems 7, 646-699 (2006) 